\title{
Unusual complication of ventriculoperitoneal shunt
}

\author{
Omotayo A. Ojoㅁ, Olumide Elebute ${ }^{2}$, Okezie O. Kanu ${ }^{1}$, \\ Olusegun Adebisi Popoola
}

${ }^{1}$ Neurosurgery Unit, Department of Surgery, Lagos University Teaching Hospital, Idi-Araba, Lagos State. Nigeria

${ }^{2}$ Peadiatric Surgery Unit, Department of Surgery, Lagos University Teaching

Hospital, Idi-Araba, Lagos State. Nigeria

\begin{abstract}
Ventriculoperitoneal shunt (VPS) is the conventional method of managing hydrocephalus until recently that endoscopic third ventriculostomy is becoming popular. The major disadvantage of VPS is the fact that it constitutes a foreign body and prone to complications such as mechanical blockage, shunt infection, shunt migration and rarely shunt protrusion. Shunt extrusion through the vagina and anus are rare but have been documented. We present a rare case of shunt migrating through the external inguinal ring into the scrotal sac in a patient.
\end{abstract}

Key words: hydrocephalus, hydroceole, ventriculoperitoneal shunt, shunt complications, processus vaginalis.

\section{Introduction}

Hydrocephalus is defined as an active distension of the ventricular system of the brain resulting from inadequate passage of cerebrospinal fluid from its point of production within the cerebral ventricles to its point of absorption into the systemic circulation.(Rekate, 2008) It has a worldwide occurrence and its incidence in the general population as documented in a Swedish study is 0.66 per 1000 life
births.(Persson, Anderson, Wiklund, \& Uvebrant, 2007) This rate may however be higher in the developing country such as Nigeria because the hydrocephalus of infective etiology is forms a large percentage of total hydrocephalic children.(Warf \& East African Neurosurgical Research, 2010) (Warf, 2005)

The standard treatment of hydrocephalus to date is ventriculoperitoneal shunt. In recent times, the advent of endoscopic third ventriculostomy is gaining popularity due to the high complication and failure rates of ventriculoperitonel shunt.(de Ribaupierre, Rilliet, Vernet, Regli, \& Villemure, 2007)

The success rate of VP shunt is in the range of $60 \%$ and its failure rate in literature is close to $40 \%$.(Piatt \& Garton, 2008) Infection rate in VP shunt is close to $20 \%$ while complication rates is about 25.8 $\%$ in developing countries.(Komolafe, Adeolu, \& Komolafe, 2008)

Failure rate of VP shunt is high because of the different complications seen after the shunt. The complications of VP shunt include infections, shunt malfunction, shunt mechanical failures include breakage and migration. Shunt migration is rare and it commonly migrates to the peritoneal cavity. The rarer presentations of shunt 
migration include migration into virginal, anus and scrotal sac. We present a shunt migration into the scrotal sac as a result of pre-existing hydrocele that was not taken into consideration before the shunt procedure.

\section{Case report}

We present a 15 month old baby who was referred to Neurosurgery clinic on account of a swollen left hemiscrotum. He was a product of full term delivery and at 6 months of life, the parents realized there was an occasional swelling of left hemiscrotum. It was only notice while the baby was crying and resolved spontaneously.

At 9 months of age, he had an episode of fever following upper respiratory tract infection. He was treated empirically at the peripheral hospital with oral antibiotics. The fever subsided and baby became well. Two weeks after he was noted to have a gradual increase in head circumference. A CT scan done showed a pan ventricular hydrocephalus. He was otherwise well.

The parents made an emergency arrangement to take him out of Nigeria for a ventriculoperitoneal shunt.

Six weeks after the VP shunt and now in Nigeria, left hemiscrotum was gradually increasing in size. A diagnosis of hydrocele was made with possible patent processus vaginalis. No attempt was made to operate on the hydrocele.

Two weeks before presentation to the Neurosurgeon in Nigeria, mother reported she could feel a hard tubular structure in the left hemiscrotum. Attempt to return to the center oversea where VP shunt was done was futile. He was then brought to us.

At presentation, he was a playful child with significant craniofacial disproportion.
There was no symptom of increasing intracranial pressure, anterior fontanel was soft and sunken, no other signs of hydrocephalus like distended scalp veins, sun set appearance of the eyes. Scars on the scalp and the abdomen signifying evidence of VP shunting.

General examination was essentially normal. The abnormal findings were in the inguinal region. Inspection revealed a swollen left hemiscrotum. No differential warmth, no tenderness on palpation. The inguinal ring was comparatively wider on the left than on the right. It could conveniently accommodate the tip of the index finger. A coil of abdominal catheter part of VP shunt was palpable. Clinical photograph demonstration the distal catheter part of the VT shunt was taken.

The only imaging done was an ultrasound scan of the pelvis and the scrotum. The distal part of the catheter was identified.

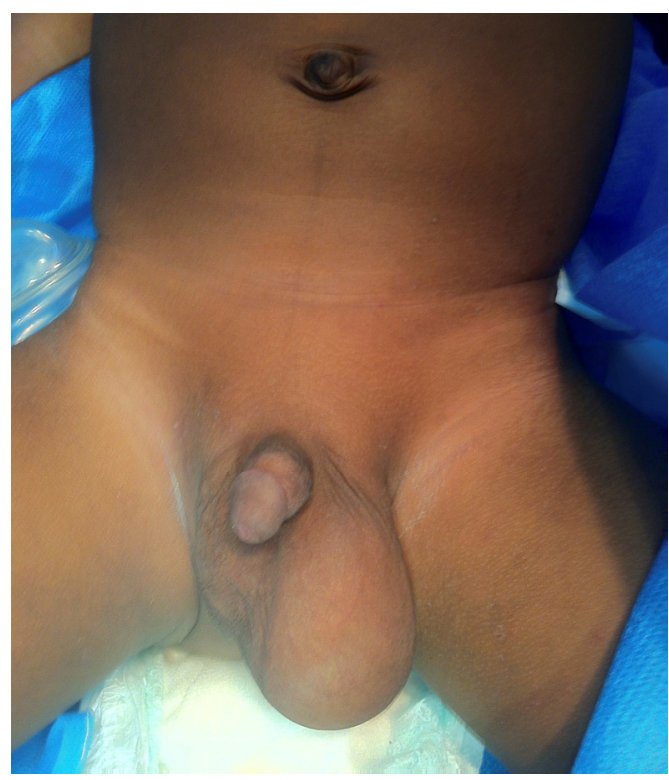

Figure 1

Baby with left scrotal hydrocele. Note the right sub chondrial incision- the entry point of the peritoneal component of VP shunt 


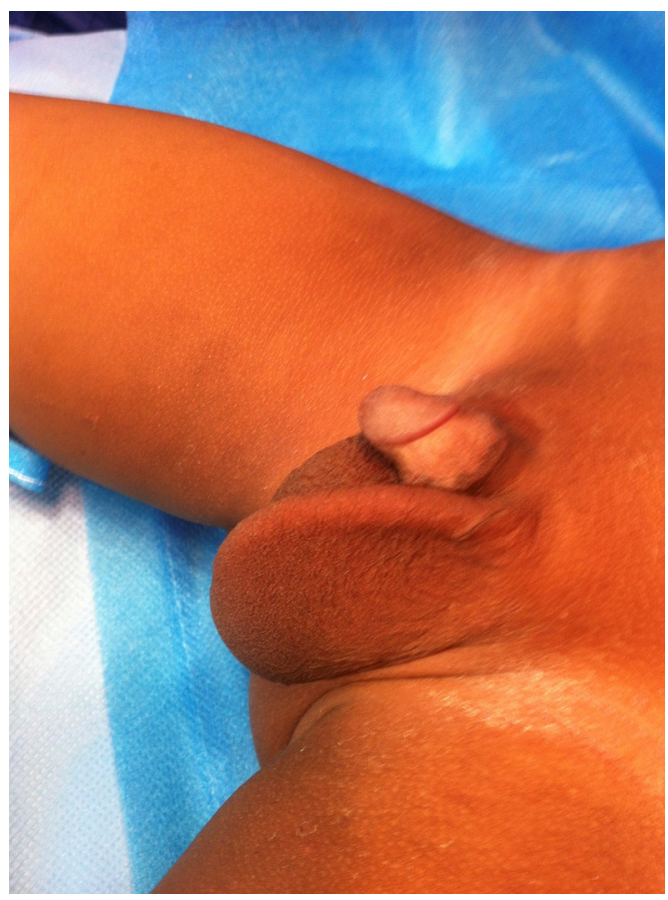

Figure 2

Distal peritoneal shunt migrating through the Left external inguinal ring into the scrotal sac in a baby with pre-existing hydrocele

He was prepared for surgery. While he was under general anesthesia, the distal end of the catheter in the left hemiscrotum was manipulated and repositioned intraperitoneally before cleaning and draping. A simple herniotomy was done without exposing the shunt. Patient did well after the surgery and swelling did not recall anymore.

\section{Discussion}

The most common complication of VP shunt in our setting is infection. This is not different from what is seen in other settings including the developed countries. The incidence of post shunt infection is a Nigerian tertiary center is $25.7 \%$ as documented by Komolafe et al.(Komolafe et al., 2008) Other reported incidence ranges from $10-20 \%$. Though its been rarely seen in different neurosurgical centers, the incidence of rarer complications are not documented. There are less than ten documented cases of scrotal migration of distal VP shunt when a search was conducted on PubMed.

A patent processus vaginalis is a potential route for distal migration of VP shunt due to increased intra-abdominal pressure. The intra-abdominal component of ventriculoperitoneal shunt wanders around the large peritoneal cavity and a patent processus vaginalis is a possible escape route for the distal tip of the shunt.

Distal migration of the shunt into scrotal sac is potentially frightening for the parents / guardians of a baby with VP shunt. Most parents are not sure what it might be, as they have probably not seen a shunt before and not expected to feel it in the scrotal sac. A proper education of all and every possible complication of VP shunt should be explained at the point of taking consent.

A shunt in the scrotal sac potentially keeps the external inguinal ring opened and there is a likelihood of bowel herniation forming an inguinoscrotal hernia. The consequences could be grief with attending obstruction and strangulation.

Although shunt migration into the scrotum is usually associated with hydrocele as in this case, its treatment is less frightening. Simple taxing of the distal shunt by serial manipulations while under anesthesia will ensure the catheter is in the peritoneum without the possibility of contaminating the sterile shunt system at surgery. It is imperative this is done under anesthesia to ensure relaxation just before a simple herniotomy is performed by the pediatric surgeon. With the closure of the external ring and without the exposure of the shunt system, the problem of shunt 
migration is sorted at the same time that of hydrocele.

\section{Conclusion}

Shunt complications are many but ensuring the processus vaginalis is not patent before the shunt procedure is done can prevent some rarer ones like migration into the scrotal sac. By inference, all children should be checked for inguinoscrotal hernia as well as inguinal hydrocele before VP shunt procedure is done. In cases where there is hydrocele or inguinoscrotal hernia concomitant with hydrocephalus, herniotomy should be done at the same time of VP shunt to prevent migration of distal shunt to the scrotal sac.

Corresponding Author:

Dr. Omotayo A Ojo

Neurosurgery Unit, Department of Surgery. Lagos University Teaching Hospital, Idi-Araba, Lagos State. Nigeria

Email :tayoojo111@yahoo.com

Tel: +2348033922181

\section{References}

1. de Ribaupierre, S., Rilliet, B., Vernet, O., Regli, L., \& Villemure, J. G. (2007). Third ventriculostomy vs ventriculoperitoneal shunt in pediatric obstructive hydrocephalus: results from a Swiss series and literature review. Childs Nerv Syst, 23(5), 527-533. doi: 10.1007/s00381-006-0283-4

2. Komolafe, E. O., Adeolu, A. A., \& Komolafe, M. A. (2008). Treatment of cerebrospinal fluid shunting complications in a Nigerian neurosurgery programme. Case illustrations and review. Pediatr Neurosurg, 44(1), 36-42. doi: 10.1159/000110660

3. Persson, E. K., Anderson, S., Wiklund, L. M., \& Uvebrant, P. (2007). Hydrocephalus in children born in 1999-2002: epidemiology, outcome and ophthalmological findings. Childs Nerv Syst, 23(10), 1111-1118. doi: 10.1007/s00381-007-0324-7

4. Piatt, J. H., Jr., \& Garton, H. J. (2008). Clinical diagnosis of ventriculoperitoneal shunt failure among children with hydrocephalus. Pediatr Emerg Care, 24(4), 201-210. doi: 10.1097/PEC.0b013e31816a8d43

5. Rekate, H. L. (2008). The definition and classification of hydrocephalus: a personal recommendation to stimulate debate. Cerebrospinal Fluid Res, 5, 2. doi: 10.1186/1743-8454-5-2

6. Warf, B. C. (2005). Hydrocephalus in Uganda: the predominance of infectious origin and primary management with endoscopic third ventriculostomy. J Neurosurg, $102(1 \quad$ Suppl), 1-15. doi: 10.3171/ped.2005.102.1.0001

7. Warf, B. C., \& East African Neurosurgical Research, Collaboration. (2010). Pediatric hydrocephalus in East Africa: prevalence, causes, treatments, and strategies for the future. World Neurosurg, 73(4), 296-300. doi: 10.1016/j.wneu.2010.02.009 